\title{
STUDY ON RISK FACTORS, CLINICAL AND THERAPEUTIC PROFILE OF CHRONIC OBSTRUCTIVE PULMONARY DISEASE PATIENTS IN GOVERNMENT GENERAL HOSPITAL
}

\author{
LAKSHMI P, SUCHARITHA J*, JAYA SINDHU M, CHARAN TEJA A, MADHURI B
}

Department of Pharmacy Practice, Sri Padmavathi School of Pharmacy, Tiruchanoor, Tirupati, Andhra Pradesh, India. Email: jannesucharitha@gmail.com

Received: 14 November 2020, Revised and Accepted: 29 December 2020

\section{ABSTRACT}

Objective: This study mainly aims to assess and evaluate risk factors, clinical and therapeutical profile in chronic obstructive pulmonary disease (COPD) patients and promote rational drug therapy; to identify the prevalence of COPD symptoms and to assess the drugs prescribed in treating COPD patients; and to evaluate patterns of diagnosing COPD in patients and determine the severity of COPD in patients using COPD assessment test (CAT).

Methods: A prospective observational study conducted in government general hospital among 220 patients for 6 months. Data were collected from patients by CAT questionnaire through interviewing each subject.

Results: The majority of the patients (36\%) were in the age group of 71-80 years. Males are more prone to the COPD (91\%). Most common initiation interdependence of these habits are 31-40 years and $61.8 \%$ are suffering with comorbidities. A total of 145 (65\%) have social habits. About $68 \%$ of the patients are suffering from occupational exposure, $78 \%$ of the patients are suffering from old pulmonary problems.

Conclusion: Clinical pharmacist main provision is providing care to individual patients by patient counseling, regarding the rational usage of drug and also providing proper education regarding the usage of nebulizers and creating awareness to the patients.

Keywords: Chronic obstructive pulmonary disease assessment test questionnaire, Interdependence, Clinical pharmacist, Rational usage, Nebulizers. (C) 2021 The Authors. Published by Innovare Academic Sciences Pvt Ltd. This is an open access article under the CC BY license (http://creativecommons.org/ licenses/by/4.0/) DOI: http://dx.doi.org/10.22159/ajpcr.2021v14i3.40245. Journal homepage: https://innovareacademics.in/journals/index.php/ajpcr

\section{INTRODUCTION}

Chronic obstructive pulmonary disease (COPD) is a leading cause of morbidity and mortality worldwide. COPD is a progressive disease characterized by airflow limitation that is not fully reversible and is associated with an abnormal inflammatory response of the lungs to noxious particles or gases. COPD is a general term that covers a variety of other disease labels including chronic obstructive airways disease and chronic obstructive lung disease [1].

Nowadays, COPD is the fourth leading cause of death worldwide and will be third leading cause of death by 2020 . COPD attributed to active smoking, ambient particulate matter pollution, household air pollution, second-hand smoke, and lead exposure was responsible for about 3.46 million of global deaths and 9.78 million of disability-adjusted life years in 2017. The goals of the GOLD organization are to increase awareness of COPD and reduce morbidity and mortality associated with the disease [2].

The most common conditions comprising COPD are chronic bronchitis and emphysema. Chronic bronchitis is a condition with chronic recurrent excessive mucus secretion into the bronchial tree with cough that is present on most days for at least 3 months of the year for at least 2 consecutive years in a patient. While chronic bronchitis is defined in clinical terms, emphysema is defined in term of anatomic pathology. Emphysema classically was defined on histologic examination at autopsy. It also has been defined as abnormal permanent enlargement of the airspaces distal to the terminal bronchioles accompanied by destruction of their walls yet without obvious fibrosis [3]. A COPD symptom in severe diseases depends on bronchitis and emphysema includes shortness of breath, wheezing, cough, chest tightness, mucus production, cyanosis, swelling of ankles, unintended weight loss, frequent airway infections, dyspnea, and orthopnea. Cigarette smoking is the most common risk factor among industrialized countries and accounts for $85-90 \%$ of cases of COPD [4].

The test used to detect the severity of COPD is COPD assessment test (CAT) it contains eight questions with score if score is present in between 1 and 10, it is mild, if it is in between 11 and 20, it is moderate, 21-30 means severe, and 31-40 it is very severe COPD [5]. Recognition of COPD as a major health problem is generally it is a slowly progressive disease.

\section{METHODS}

\section{Study design and method of data collection}

Our study was a prospective observational study which was conducted in inpatients of general medicine, pulmonology, and IDH departments of Sri Venkateswara Ramnarain Ruia Government General Hospital.

A specially designed data collection form with the patient demographic details, diagnosis, treatment chart, history of disease and treatment, and CAT questionnaire was made. Patients who admitted in general medicine, pulmonology, and IDH departments were considered according to the inclusion and exclusion criteria for a period of 6 months. All the collected data were subjected to statistical analysis using Excel spread sheet.

\section{Study design}

This was a prospective observational study.

Study period

Six months (June-December).

Sample size

Two hundred and twenty patients. 


\section{Inclusion criteria}

COPD patients who admitted in pulmonology, IDH, and general medicine wards during the study period were included in the study.

\section{Exclusion criteria}

Out patients, pediatrics, pregnant and lactating women, and seropositive patients were excluded from the study.

\section{Study materials}

Data collection form, Micromedex solutions.

\section{Ethical committee approval}

Approval number - SPSP/2019-2020/PD05.

\section{Statistical analysis}

It was performed using Microsoft office Excel 2016 for analyzing the results in the form of charts and percentages.

\section{RESULTS}

A prospective observational study was conducted for a period of 6 months from June to December in inpatients of general medicine, pulmonology, and IDH departments at a tertiary care hospital, Tirupati.

A total of 220 cases (prescriptions) were collected during the study period. Out of which, we categorize the prescriptions into genderwise distribution, age-wise distribution, and also based on risk factors and clinical manifestations. The following data or tables indicate that how many patients affected with this disease with different signs and symptoms and risk factors. Out of which, we further categorize 220 prescriptions into different categories such as:

Fig. 1 shows that out of 220 patients, the highest number of patients was under males followed by females, that is, $200(91 \%)$ and $20(9 \%)$ patients, respectively.

Fig. 2, as shown in the above fig, out of 220 patients, the highest number of COPD patients was under the age group of 71-80 followed by 81-90, $61-70,51-60,41-50,91-100$, and 31-40, that is, $80,52,29,24,21,11$, and 3 patients, respectively.

Fig. 3 indicates that out of 220 patients, 198 patients are without known case of COPD and 22 patients are with known case of COPD, respectively.

Fig. 4, as per the above fig, out of 220 patients, 190 patients are with symptom of cough followed by 48 with edema, pallor in 83 , and dyspnea in 166 , and wheeze in 167 patients, respectively.

Fig. 5 indicates that, among 220 patients, 171 patients are without old pulmonary problems and 49 patients are with old pulmonary problems, respectively.

Fig. 6 indicates that out of 220 patients, 146 patients are current smokers, 64 are no smokers, and 10 patients are ex-smokers, respectively.

Fig. 7 shows that out of 220 patients, 151 patients are exposed and 69 patients are not exposed to occupation, respectively.

Fig. 8 indicates that out of 220 patients, 123 patients are with sputum and 97 patients are without sputum, respectively.

Fig. 9 indicates that out of 220 patients, 118 patients are without exacerbations followed by 102 patients with exacerbations, respectively.

Fig. 10 shows that out of 220 patients, 144 patients are consuming only alcohol, 145 patients consuming only smoking, 44 patients are consuming both alcohol and smoking, and 23 patients are not consuming alcohol and smoking, respectively.

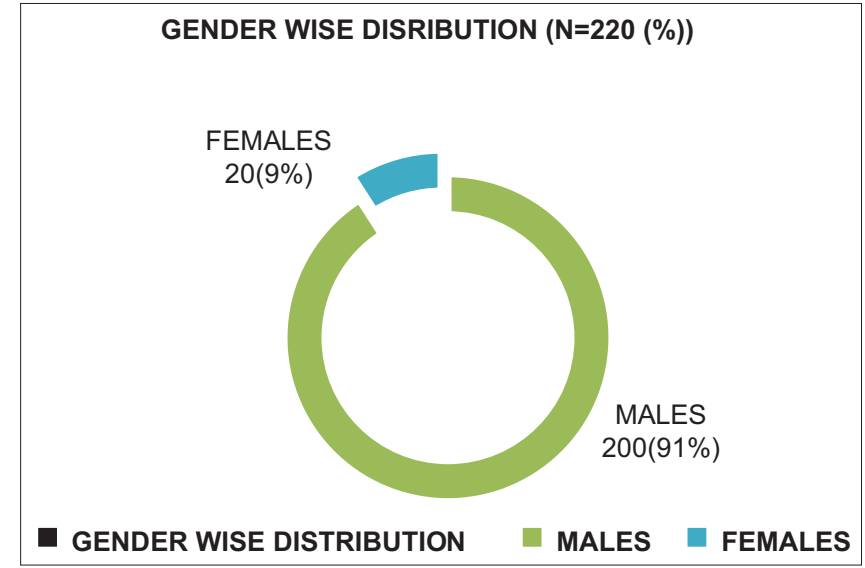

Fig. 1: Gender-wise distribution

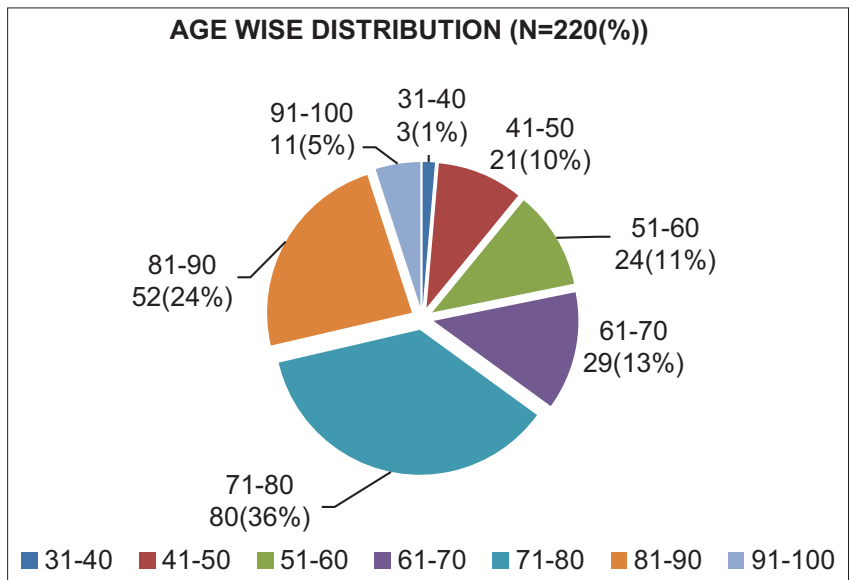

Fig. 2: Age-wise distribution

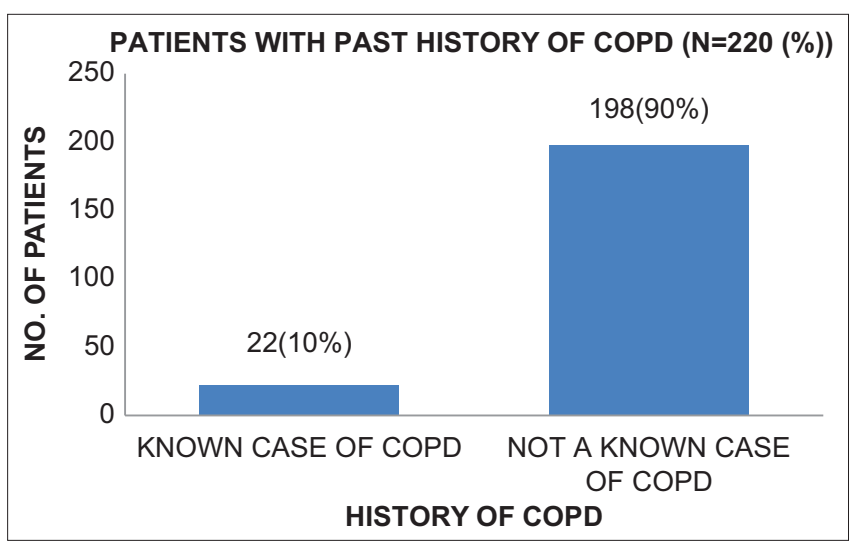

Fig. 3: Patients with a history of chronic obstructive pulmonary disease

Fig. 11 indicates that out of 220 patients, highest no. of patients having risk factor of smoking and age followed by exposed to dust, alcohol, gender, mucociliary clearance, and allergens, that is, 171, 151, 146, 146, 159,119 , and 18 patients, respectively.

Table 1 indicates that out of 220 patients, 22 patients with old pulmonary tuberculosis followed by 16 with hypertension, congestive heart failure in 4, urinary tract infections in 3 , diabetes mellitus in 12 , gastritis in 12 , chronic kidney disease in 5 , cor pulmonale in 22 , acute exacerbations in 31 , and respiratory failure in 10 patients, respectively. 


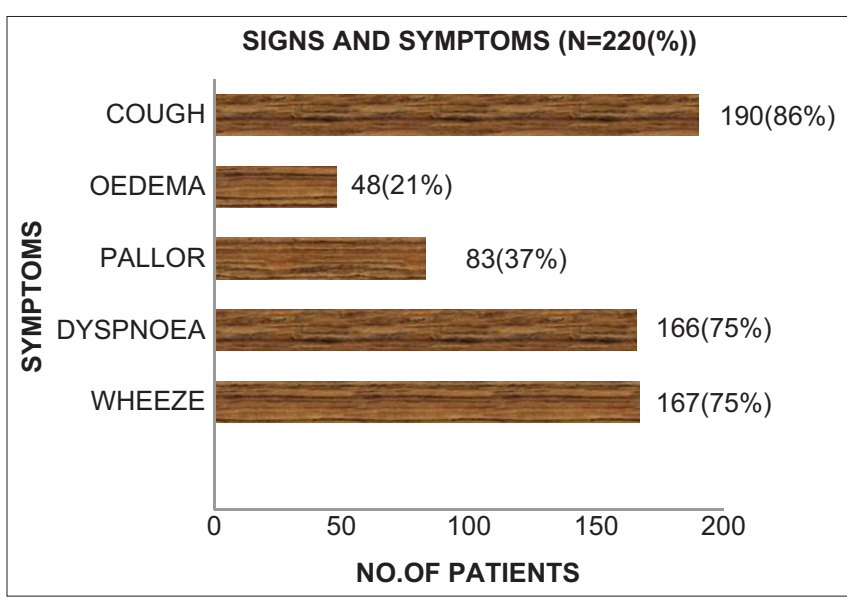

Fig. 4: Based on signs and symptoms

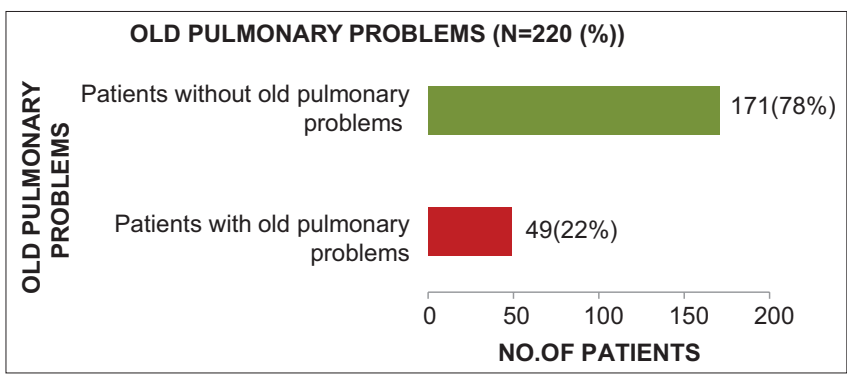

Fig. 5: Old pulmonary problems

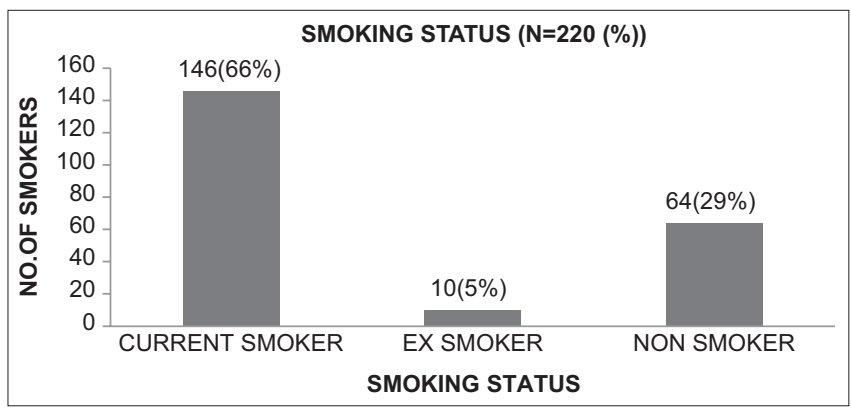

Fig. 6: Smoking status

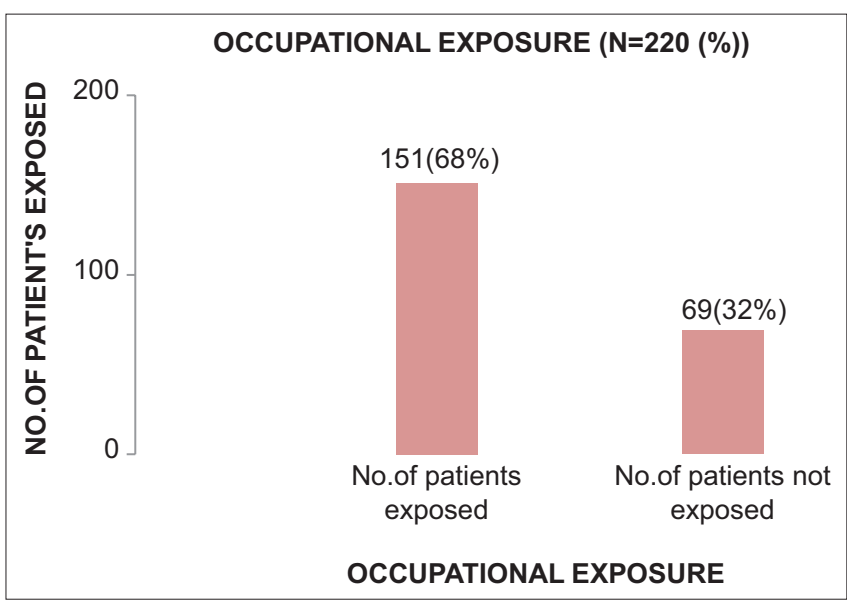

Fig. 7: Occupational exposure

Fig. 12 shows that out of 220 patients, the highest number of patients was under the age group of 41-50, 31-40, 51-60, 61-70, 71-80, 81-90, and $91-100$ years, that is, $61,52,32,24,10,5$, and 2 COPD patients, respectively.

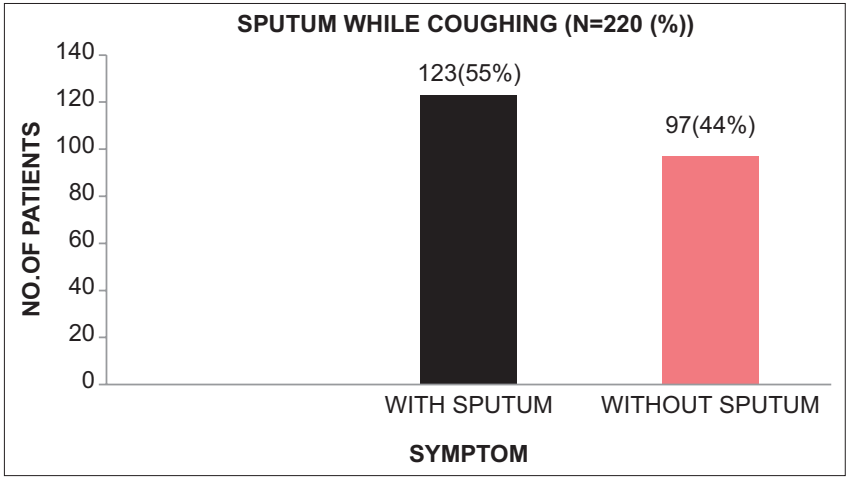

Fig. 8: Patient examination

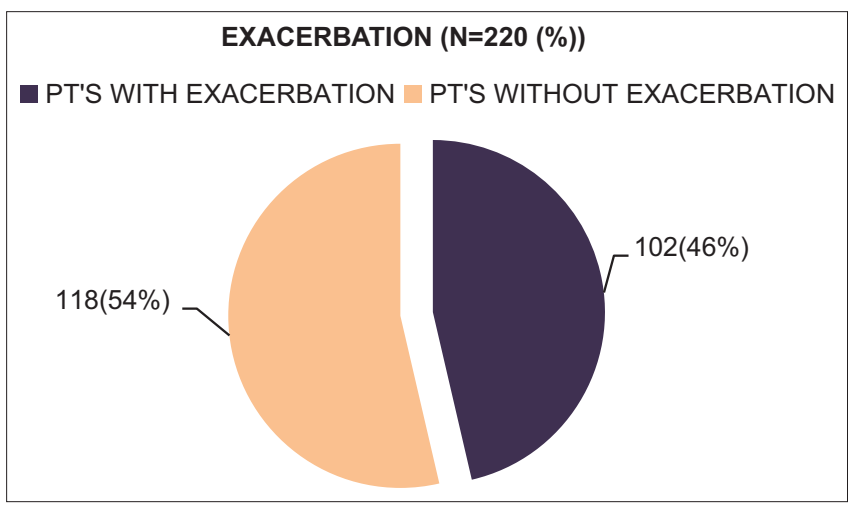

Fig. 9: Patient examination

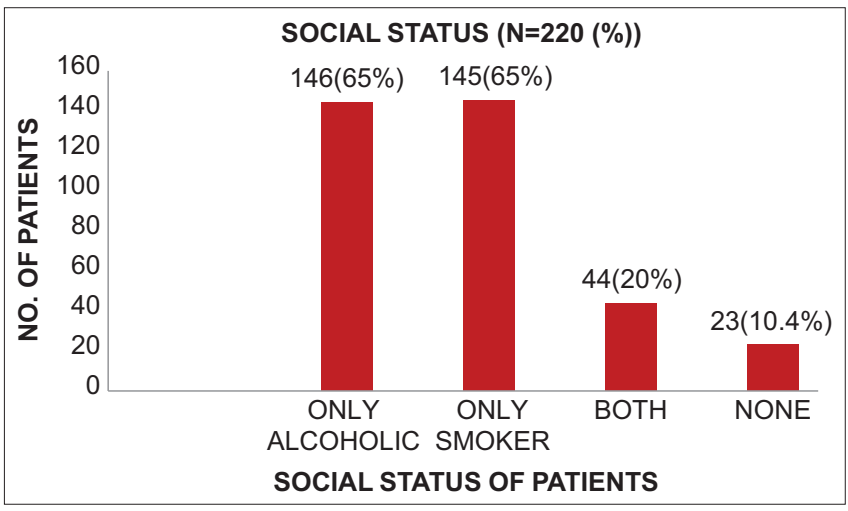

Fig. 10: Social status

Fig. 13 indicates that out of 220 patients, 63 patients were diagnosed by X-ray, 44 diagnosed by computed tomography (CT) scan, and 23 patients are diagnosed by ultrasonography (USG), respectively.

Fig. 14 indicates that out of 220 patients, $48 \%$ contains $4-6$ drugs, $41 \%$ contains $7-9$ drugs, $5 \%$ contains $10-12$ drugs, $4 \%$ contains $1-3$ drugs, and $2 \%$ contains > or equal to 13 drugs, respectively.

Table 2 indicates that among 220 COPD patients, 196 patients are prescribed with deriphyllin followed by methylprednisolone in 118, duolin+salbutamol in 4, budecort+salbutamol in 75, duolin+budecort in 44 , Foracort in 89 , ambroxol in 24 , salbutamol in 77 , and hydrocortisone in 46 patients, respectively.

Table 3 indicates that out of 220 patients, the drugs prescribed are Pantop in 184 patients followed by ceftriaxone in 26 , cef+salbactum in 74 , paracetamol in 122 , Lasix in 75 , augmentin in 56 , cetirizine in 27 , 


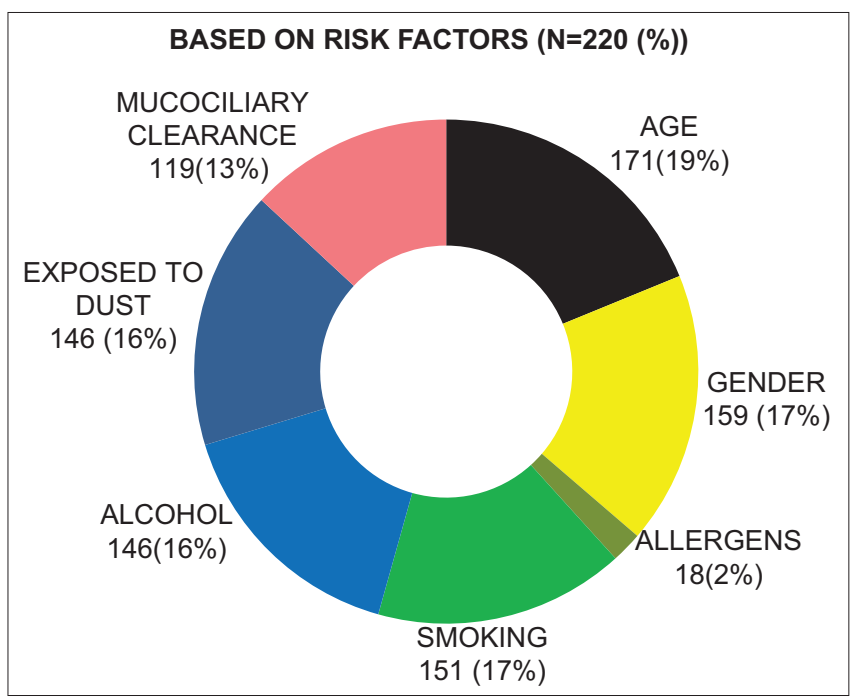

Fig. 11: Risk factors

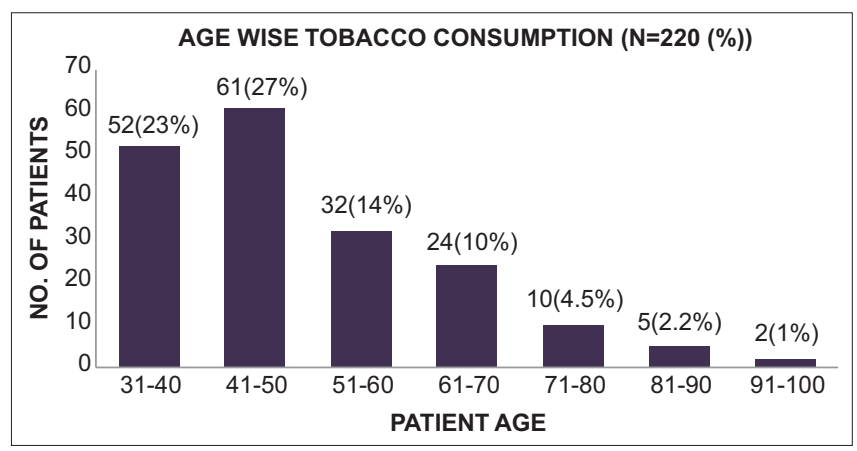

Fig. 12: Age-wise tobacco consumption

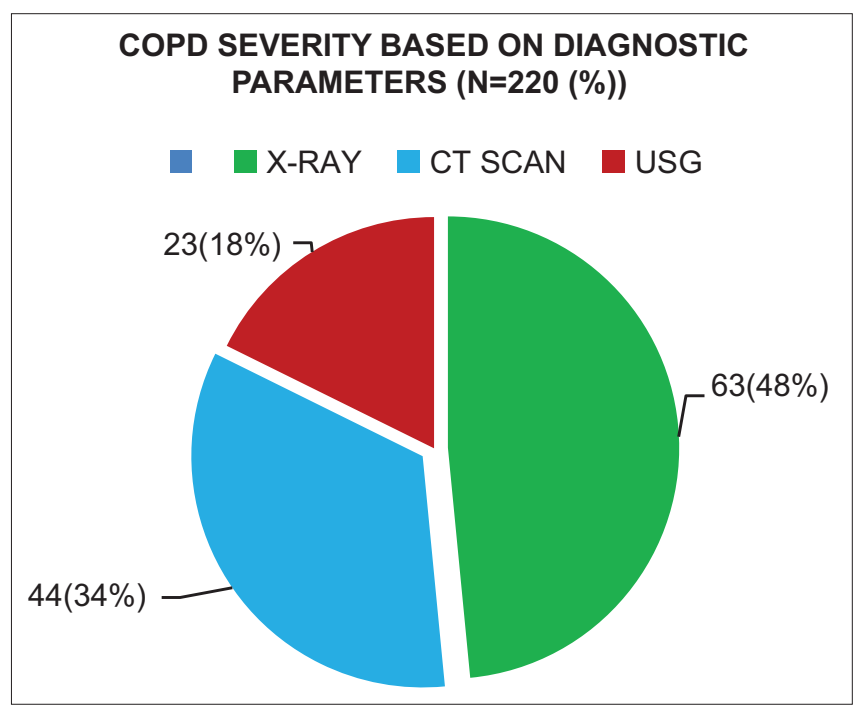

Fig. 13: Diagnostic parameters

amlodipine in 39, metrogyl in 33, sucralfate in 21, and B Complex in 188 patients, respectively.

Fig. 15 indicates that out of 220 patients, based on questionnaire, 180 patients are with severe COPD followed by 28 moderate COPD and 12 very severe COPD patients, respectively.
Table 1: Classification based on comorbidities

\begin{tabular}{lll}
\hline S. No. & Comorbidities & No. of patients $(\mathbf{n = 2 2 0}[\%] \mathbf{~}$ \\
\hline 1. & Old PTB & $22(10)$ \\
2. & Hypertension & $16(7.2)$ \\
3. & CHF & $4(1.8)$ \\
4. & UTI & $3(1.3)$ \\
5. & DM & $12(5.4)$ \\
6. & Gastritis & $12(5.4)$ \\
7. & CKD & $5(2.2)$ \\
8. & Cor pulmonale & $22(10)$ \\
9. & Acute exacerbations & $31(14)$ \\
10. & Respiratory failure & $10(4.5)$ \\
\hline
\end{tabular}

PTB: Pulmonary tuberculosis, UTI: Urinary tract infections, CKD: Chronic kidney disease

Table 2: Classification based on prescribed therapy in COPD patients

\begin{tabular}{lll}
\hline S. No. & Prescribed therapy & No. of patients $(\mathbf{n = 2 2 0}[\%])$ \\
\hline 1. & Neb. Duolin+Salbutamol & $4(2)$ \\
2. & Neb. Salbactum+Budecort & $75(34)$ \\
3. & Neb. Duolin+Budecort & $44(20)$ \\
4. & Foracort & $89(40)$ \\
5. & Ambroxol & $24(11)$ \\
6. & Salbutamol & $77(35)$ \\
7. & Deriphyllin & $196(89)$ \\
8. & Hydrocortisone & $46(21)$ \\
9. & Methylprednisolone & $118(54)$ \\
\hline
\end{tabular}

COPD: Chronic obstructive pulmonary disease

Table 3: List of medications used to treat other comorbidities in COPD patients

\begin{tabular}{lll}
\hline S. No. & Drugs & No. of drugs $(\mathbf{n = 2 2 0}(\mathbf{\%}) \mathbf{)}$ \\
\hline 1. & Pantoprazole & $184(83)$ \\
2. & Ceftriaxone & $26(11.8)$ \\
3. & CEF+Salbactum & $74(34)$ \\
4. & Acetaminophen & $122(55)$ \\
5. & Furosemide & $75(34)$ \\
6. & Amoxyclav & $56(25)$ \\
7. & Cetirizine & $27(12)$ \\
8. & Amlodipine & $39(18)$ \\
9. & Metronidazole & $33(15)$ \\
10. & Sucralfate & $21(10)$ \\
11. & B Complex & $188(85)$ \\
\hline
\end{tabular}

COPD: Chronic obstructive pulmonary disease

\section{DISCUSSION}

Chronic obstructive pulmonary disease is a growing global health concern affecting over a million of peoples worldwide and contributing to million deaths every year. This disease that is characterized by persistent and progressive airflow limitation often suffers from remarkable respiratory symptoms. This substantial burden of COPD reduces physical and psychological functioning, ultimately decreasing health-related quality of life.

In the present study, 220 subjects were analyzed regarding study on risk factors, clinical and therapeutic profile of COPD patients. Average drugs per prescription were found to be six drugs in 220 prescriptions. The study revealed that majority of patients hospitalized were in the age group of 31-40 years which were $3(1 \%)$ patients followed by $41-50$ years were $21(10 \%), 51-60$ years were $24(11 \%), 61-70$ years were 29 (13\%), 71-80 years were 80 (36\%), 81-90 years were $52(64 \%)$, and 91-100 years were $11(5 \%)$, respectively showing that majority of the hospitalized patients fall under the age group range 71-80 years with 


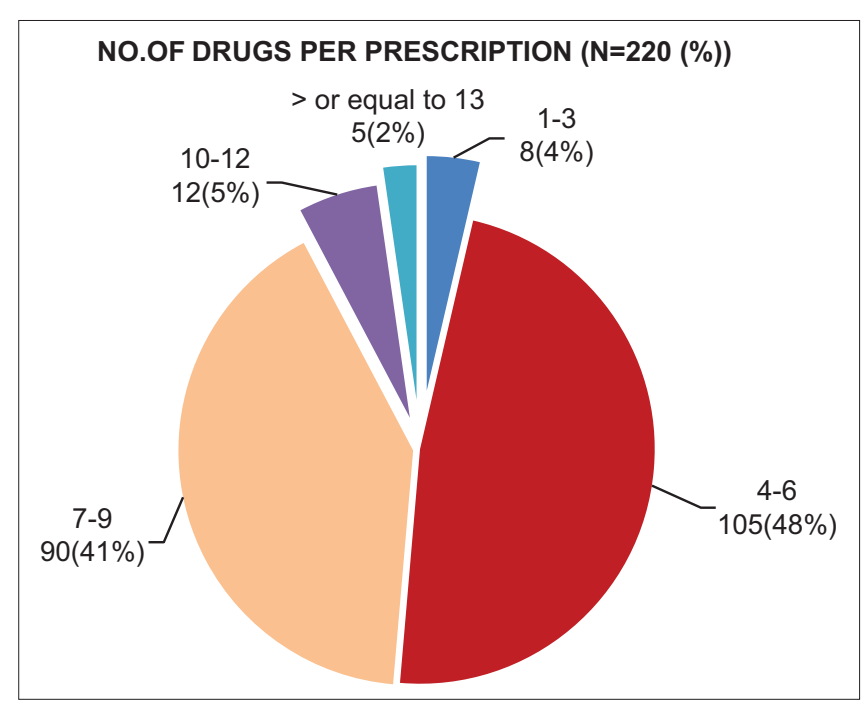

Fig. 14: Drugs per prescription

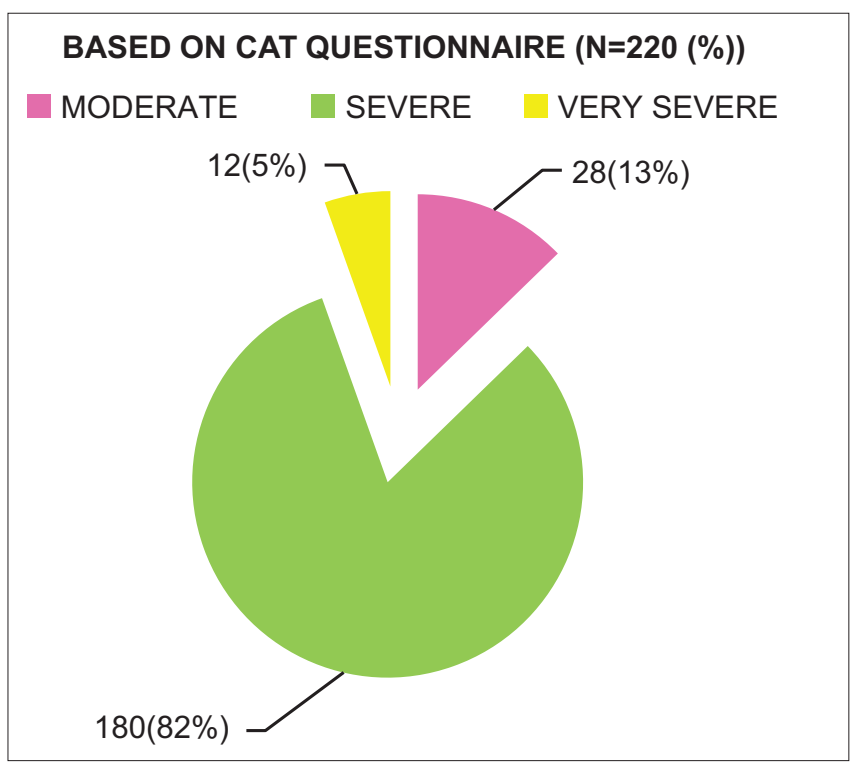

Fig. 15: Questionnaire

80 patients [6]. Among 220 patient's, males were 200 (91\%) whereas females were $20(9 \%)$, indicating that male patients are dominant over females. This may be due to males who are more prone to consumption of alcohol, smoking, and tobacco than females [6,7]. In 220 patients, 198 patients are with a known case of COPD and remaining 22 patients are without a known case of COPD [8]. A total of 220 patients based on the signs and symptoms mostly the patients are present with complaints of cough, wheeze, dyspnea, pallor, and edema that is 190,167,165, 83, and 43 patients, respectively $[9,10]$.

Among 220 patients of COPD, one of the main leading causes is the presence of old pulmonary problems other than COPD can lead cause chronic obstructive pulmonary disease that is $171(78 \%)$ were present with old problems whereas $49(22 \%)$ are without any previous pulmonary problems [11]. The most common age of initiation of smoking and tobacco consumption is between 31 and 40 years this may be due to stress-related issues and may be due to occupational pressure [12]. The prevalence of smoking use in the present study is, $146(66 \%)$ were current smokers followed by $10(5 \%)$ were ex-smokers and $64(29 \%)$ were non-smokers $[9,13]$.

The occupational exposure of COPD is one of the most etiological factors in this study, 151 (68\%) patients were exposed and 69 (32\%) were not exposed, there are $62 \%$ of the patients suffering from either one or two or three or more than 3 comorbidities and also the maximum of the patients without comorbidities will be prone them in near coming days $[9,14]$. The study observed that the signs and symptoms among 220 patients were suffered with cough 190 (86\%) followed by wheeze were 167 (75\%), dyspnea patients were 166 (75\%), and other symptoms such as pallor and edema $[9,15]$. The sputum production and exacerbations are the major symptoms in this study that were $123(55 \%)$ have a symptom of sputum production and 102 (46\%) have a symptom of exacerbations [16]. The present study revealed that 146 patients are initially having habit of smoking consumption and 144 patients are having a habit of alcohol. Further, the presence of any one of the habit leads to initiating the other habit and the use of one may act as potentiating factor for the use of others as with this study. Studies suggest that people who are dependent on alcohol are 3 times more likely to smoke and people who are dependent on smoke are 4 times more likely to dependent on alcohol. In this study, the highest risk factor involved was age factor in $171(77 \%)$ patients followed by smoking 151 (68\%), alcohol $146(66 \%)$, gender 159 (72\%), exposure to dust 146 (66\%), allergens 18 (8\%), and other risk factors [17].

Among 220 patients, 63 patients were diagnosed by X-ray, 44 diagnosed by CT scan, and 23 patients are diagnosed by USG along with these diagnostic tests also some of the diagnostic tests [18]. A total of 200 COPD patients, 196 patients are prescribed with theophylline followed by corticosteroids in 118, bronchodilators in 122, oxygen therapy in 89 , and mucolytics in 101 patients along with some of the other symptomatic drugs were prescribed $[19,20]$. Using the CAT assessment test among 220 patients, the highest number of COPD was under the score of $21-30$ that is $180(82 \%)$ followed by $11-20$ that is $28(13 \%)$ and 31-40 $12(5 \%)$ [5].

\section{CONCLUSION}

The present study emphasizes about the risk factors, clinical and therapeutic profile among COPD patients. With this study, we conclude that along with proper medications, health educational interventions about the usage of nebulizers and rational usage of drugs will majorly help in reducing the worsening and reoccurring of chronic obstructive pulmonary disease in future. As a clinical pharmacist we provide feedback to the physicians by assessing the COPD patients prescription and we also provide proper education to the patients regarding the usage of drugs which helps in increasing the patients quality of life and also decreases the severity of disease in the patients. Hence, coordination with clinical pharmacist along with physicians as a health-care team is necessary to improve the health conditions among COPD patients.

\section{ACKNOWLEDGMENT}

The authors offer sincere thanks to the guide Mrs. P. Lakshmi for providing support and guidance; we also extend our sincere thanks to the patients and their families for supporting this study.

\section{AUTHORS' CONTRIBUTIONS}

All the authors have prepared the conception, data collection, data analysis, interpretation and drafting of the article, and also discussed the methods, results, and contributed to the final manuscript. Mrs. P. Lakshmi supervised the whole work until the completion of manuscript.

\section{CONFLICTS OF INTEREST}

No conflicts of interest, financial, or otherwise.

\section{AUTHORS' FUNDING}

This research received no external funding.

\section{REFERENCES}

1. Walker R, Whittlesea C. Clinical Pharmacy and Therapeutics. $12^{\text {th }} \mathrm{ed}$. New York: Churchill Living Stone Elsevier; 2012. p. 431-32. 
2. Dipiro JT, Robert L. Pharmacotherapy a Pathological Approach. $6^{\text {th }}$ ed. New York: McGraw-Hill Medical Publishing Division; 1999. p. 537-9.

3. Kasper D, Fauci A, Hauser S, Longo D, Jameson J. Harrison's Principles of Internal Medicine. $19^{\text {th }}$ ed. New York: McGraw-Hill Medical Publishing Division; 2008. p. 1632-6.

4. Innes A. Davidson's Essentials of Medicine. $2^{\text {nd }}$ ed. New York: Churchill Living Stone Elsevier; 2016. p. 265-67.

5. Jones PW, Harding G. Development and first validation of the COPD assessment test. Eur Respir J 2009;34:648-54.

6. Kristen E, Melissa R. The impact of age on outcomes in chronic obstructive pulmonary disease differs by relationship status. Natl Inst Health 2014;37:654-63.

7. Peter J. Sex differences in chronic obstructive pulmonary disease mechanisms. Am J Respir Crit Care Med 2016;193:813-4

8. Ioanna T, Donna G. Four patients with a history of acute exacerbations of COPD: Implementing the CHEST/Canadian thoracic society guidelines for Preventing exacerbations. NPJ Prim Care Respir Med 2015;23:1-7.

9. Amar R, Pankti K. Etiology and clinical profile of COPD in nonsmokers. Int J Adv Med 2018;5:1100-4

10. Barnes PJ, Celli BR. Systemic manifestations and comorbidities of COPD. Eur Respir J 2008;33:1165-85.

11. Hammad Q, Amir S, Nicola A. Chronic obstructive pulmonary disease exacerbations latest evidence and clinical implications. Ther Adv Chron Dis 2014;5:212-27.

12. Prescott G, Graham B, Eugene B, Stephanie A. Clinical significance of symptoms in smokers with preserved pulmonary function. N Engl J Med 2018;374:1811-21.

13. Lalmolda C, Martinez N, Bare N, Teixido M, Epelde F, Monso E. Effect of a rehabilitation-based chronic disease management program targeting severe COPD exacerbations. Int J COPD 2017;12:2531-8.

14. Younmo C, Jongln L, Min C, Wonseon C, Hyoung R. Work related COPD after years of occupational exposure. Ann Occup Environ Med 2015;27:1-5.

15. Frits M, Carolyn L. Co-morbidities in patients with COPD and pulmonary rehabilitation. Series Pulm Rehabil 2014;23:131-41.

16. Victoria B, Priya V, Patrick M. Lung microbiology and exacerbations in COPD. Int J COPD 2012;7:555-69.

17. Ipsita S, Rajat D, Mehedi H, Amit W, Malabika S. Prevalence and risk factors of Chronic Obstructive Pulmonary Disease in Bangladesh. A systematic review. Cureus 2019;11:e3970.

18. Rainer B, Wuulf P. The diagnosis of chronic obstructive pulmonary disease. Cont Med Educ 2014;111:834-46.

19. Christine J. Drugs for chronic obstructive pulmonary disease. Aust Presc 2017;40:15-9.

20. Sharon R, Ravi K. Recent advances in the management of chronic obstructive pulmonary disease. F1000Res 2017;19:1-8. 